Determinantes sociais nas escolhas profissionais: uma análise sobre o curso normal.

Revista Ensaios, vol. 15, jul-dez de 2019.

\title{
Determinantes sociais nas escolhas profissionais: uma análise sobre o curso normal
}

Bruna Navarro Julião ${ }^{1}$

Resumo: Tendo em vista o amplo debate sobre vocação profissional e trajetórias educacionais e profissionais, este artigo tem como objetivo analisar os determinantes socioeconômicos que influenciam as trajetórias de estudantes que cursam o curso normal de nível médio. O debate é feito à luz do conceito de causalidade do provável, que indica o modo como as escolhas são estruturadas tendo em vista as possibilidades de concretização. Foram utilizados dados do INEP e feitas entrevistas semiestruturadas com alunos da mais antiga escola que oferece este curso do país. Os resultados indicam que o curso normal possui papel fundamental no imaginário de possibilidades de mobilidade social de seus estudantes, ainda que nem sempre almejam o magistério como profissão.

Palavras-chave: Curso normal, magistério, determinantes sociais, vocação, formação de professor.

\section{Social determinants in professional choices: A analysis of the normal course}

Abstract: In view of or broad debate about professional vocation and educational and professional trajectories, this article aims to analyze the socioeconomic determinants that influence students in their choice of the normal high school course. The debate is held in the light of the concept of probable causality, which indicates how options are structured in view of the possibilities for their realization. Data from the Inep and semi-structured interviews were used with students from the oldest school offering this course in the country. The results that the normal course has have a fundamental role in the imagination of possibilities of social mobility of its students, but which are not always the same or teaching as a profession.

Keywords: Normal course, teaching, social determinants, vocation, teacher education

\footnotetext{
${ }^{1}$ Licenciada em Ciências Sociais pela Universidade Federal Fluminense (UFF). Brasil, Niterói, Rio de Janeiro. brunanavarro@id.uff.br.
} 
Determinantes sociais nas escolhas profissionais: uma análise sobre o curso normal.

Revista Ensaios, vol. 15, jul-dez de 2019.

Muito se ouve falar em "dom" e "vocação" no que diz respeito às aspirações profissionais dos indivíduos. Ainda hoje, muitas pessoas acreditam em uma espécie de "tendência inata" que dita o futuro das pessoas em suas escolhas profissionais. A questão que fica é, de fato, as pessoas realmente possuem dons e/ou vocação para fazer suas escolhas educacionais e profissionais ou possuem outros determinantes em suas vidas que as orientam e as condicionam a alguns caminhos previamente determinados?

Buscando colocar em discussão e consequentemente analisar a noção de dom natural e/ou vocação para a escolha das profissões, a Sociologia vem debatendo em que medida as escolhas profissionais são condicionadas pela posição social dos indivíduos na estrutura social.

A competência de escolha, segundo Bourdieu (1998), é um fator de influência determinante das estratégias traçadas por aqueles que podem ter uma previsão de seus futuros a partir, inclusive, das escolhas que farão. Isso quer dizer que, a possibilidade de algumas "escolhas" já é desigual por si só, já que reflete que nem todos possuem as condições necessárias, ou, competências, para perceberem os resultados que virão a partir das escolhas que fizerem. Assim, é possível observar uma certa causalidade entre, por exemplo, estudantes de classes mais favorecidas socioeconomicamente indo para cursos como Medicina, Engenharias e afins, enquanto as classes menos favorecidas se direcionam para cursos entendidos como de menor prestígio, como as licenciaturas.

Esta pesquisa tem como objetivo analisar em que medida as trajetórias educacionais e profissionais estão relacionadas aos determinantes sociais e econômicos dos indivíduos, tendo em vista o processo de escolha do Curso Normal, que habilita para docência nas primeiras séries do ensino básico. Esse tipo de formação de nível médio vem perdendo lugar desde a promulgação da Lei de Diretrizes e Bases da Educação Nacional (LDB) de 1996 (BRASIL, 1996), que estipulou que a formação de professores se dê em nível superior, com exceção da formação de professores pelo curso normal no ensino médio, ou curso de magistério, ainda aceito para a educação infantil e para os primeiros anos do ensino fundamental I.

Nesse contexto, é importante considerar como se dá o processo de escolha por um tipo de formação que vem perdendo lugar no contexto mais amplo de habilitação para a 
Determinantes sociais nas escolhas profissionais: uma análise sobre o curso normal.

Revista Ensaios, vol. 15, jul-dez de 2019.

docência e entender as motivações, especificidades e regularidades nas características socioeconômicas dos estudantes que cursam o Curso Normal de ensino médio. A hipótese é de que são os estudantes de origem socioeconômica menos privilegiada que cursam esse nível de ensino, justificando suas trajetórias através da noção de vocação para docência.

Para isso, após essa introdução, a primeira parte do texto analisa o debate teórico existente sobre vocação, com base em alguns autores importantes na discussão sobre o conceito. Busca-se também analisar o processo de formação docente e entender o lugar que a docência ocupa na hierarquia das ocupações. A segunda parte do texto analisa a formação docente em um dos mais tradicionais colégios de formação de professores do país. Na terceira parte, analisa-se as entrevistas realizadas com dez alunos do Curso Normal, buscando, dessa maneira, compreender as motivações na escolha pelo normal, observando o contexto socioeconômico desses estudantes.

\section{3) O debate sobre vocação, formação docente e estratificação da ocupação.}

De maneira geral, o debate sobre vocação indica uma certa predisposição do indivíduo para atuar em uma profissão específica. Este item irá abordar o conceito de vocação a partir do debate sociológico, identificando neste processo os determinantes sociais e econômicos que atuam nas trajetórias educacionais e ocupacionais dos indivíduos.

O sociólogo Max Weber (2004) aponta vocação como o destino ou a tarefa determinada para cada sujeito em sua trajetória. $\mathrm{O}$ autor procurou entender como o processo de desencantamento do mundo, ou seja, o processo de racionalização do agir dos indivíduos, torna-se um elemento definidor da organização da sociedade capitalista moderna.

[...] O indivíduo deveria permanecer de uma vez por todas na condição e na vocação em que Deus o houvesse colocado, e deveria restringir suas atividades mundanas aos limites a ele impostos pela condição de vida estabelecida. [...] crença cada vez mais intensa na divina providência, a qual identifica a absoluta obediência à divina vontade, com a aceitação incondicional das coisas como elas são. (WEBER, 2004, p.77). 
Determinantes sociais nas escolhas profissionais: uma análise sobre o curso normal.

Revista Ensaios, vol. 15, jul-dez de 2019.

Com o foco nas razões práticas dos indivíduos, Bourdieu (1979), chama a atenção para a imanente relação do habitus com o campo ao qual o indivíduo é pertencente. Uma vez que o habitus é uma forma de saber agir e tomar decisões adquiridas dentro de um campo, esse indivíduo torna-se agente a partir daquilo que apreendeu no meio em que está inserido. Logo, cada campo definirá autonomamente sua própria lógica de funcionamento e os sujeitos ali inseridos absorverão as regras necessárias para a manutenção e permanência de alguns lugares dentro daquele campo, regras essas que são estabelecidas através das ações sociais.

De acordo com o autor, as práticas sociais não são meramente ações mecânicas produzidas e influenciadas pelas estruturas presentes na sociedade. Estas são o resultado das transformações pelas quais o habitus sofre em decorrência das relações que os agentes estabelecem com seus campos determinados e, consequentemente, pelas redes sociais que são criadas na circulação entre os diferentes campos desse espaço social.

Para Bourdieu, as condições de acumulação do capital são diretamente proporcionais às oportunidades do jogo que esses agentes encontram dentro de seus campos sociais, logo, as oportunidades não são aleatórias, já que estas são condicionadas socialmente aos agentes dentro desses campos. Dentro da lógica de "jogo", é evidente que, seguindo a ideia de Bourdieu, quanto maior o volume de capital, maiores serão as chances de o indivíduo dominar as estratégias do "jogo" e, consequentemente, se planejar para as consequências do futuro norteando-se por aquilo que pretende alcançar. Para além, os indivíduos que conseguem circular em um maior número de campos distintos ampliam suas chances de alcançar posições sociais mais elevadas dentro da estratificação social, justamente por conta de seu amplo volume de capitais diferenciados adquiridos na circulação dentro de diferentes campos o que amplia suas visões e possibilidades dentro da lógica desse "jogo".

Segundo Paul e Valle Silva (1998), pode-se entender que a escolha do curso, seja ela no Ensino Médio, seja no Ensino Superior, diz respeito também a diversas possibilidades que são vislumbradas para um futuro que se almeja. A escolha de carreira, assim como a escolha do curso pelos estudantes, dita muito sobre suas trajetórias e percepções sobre os resultados e repercussões que terão a partir de suas escolhas. Diversas 
Determinantes sociais nas escolhas profissionais: uma análise sobre o curso normal.

Revista Ensaios, vol. 15, jul-dez de 2019.

variáveis influenciam no processo de escolha da carreira e, em geral, as pessoas optam por cursos onde suas chances não apenas de ingresso, mas de permanência, também são maiores e mais possíveis de acordo com suas realidades.

A vocação, ou aptidões naturais, como aponta Bisseret (1979), são utilizadas para explicar e/ou justificar as diferenças e desigualdades sociais entre os indivíduos. Aqui, em específico, pensando as trajetórias escolares e consequentemente profissionais, poderíamos dizer que, se, supostamente todos os indivíduos possuem as mesmas capacidades intelectual e cognitiva, e, a própria escola é fornecedora das oportunidades de os indivíduos provarem suas aptidões, "Diferentes e territorialmente desiguais, somente elas (aptidões) permitem explicar a diferenciação e a hierarquização dos indivíduos e dos grupos sociais. ”. (BISSERET, p.2).

Ao passo que, de acordo com Bourdieu (1998), as pessoas fazem suas escolhas tendo em vista as possibilidades viáveis dentro de suas trajetórias. Assim, a causalidade do provável diz muito sobre o próprio capital cultural e informacional que diferencia as pessoas que podem escolher e as que são levadas a escolhas premeditadas.

Deste modo, Bourdieu aponta que a situação para esses sujeitos,

\begin{abstract}
A situação-limite dos subproletários, cuja total impotência condena à alternância entre o onirismo e a demissão, torna visível um dos aspectos da relação entre o poder atual e as disposições: as práticas sem economia nem estratégia desses homens sem futuro e, em particular, o abandono fatalista à fecundidade natural, testemunham que, aquém de um certo patamar, não é possível constituir a própria disposição estratégica que implica a referência prática a um futuro, por vezes muito distante, como se ambição efetiva de dominar o futuro fosse, inconscientemente, proporcional ao poder efetivo para dominá-lo. (BOURDIEU, 1998, p.89).
\end{abstract}

Assim, os desejos reais diferenciam-se das possibilidades práticas que esses sujeitos enxergam. A vocação efetiva dentro de determinadas condições sociais, referencia-se às condições de realização daquilo que o sujeito se propõe, ajustando-se, portanto, às potencialidades objetivas do indivíduo. Isso significa dizer que quem possui melhores condições sociais, consequentemente possui mais possibilidades de escolhas e de caminhos. Enquanto que na situação contrária, quanto piores as condições sociais, econômicas e afins, menores serão as possibilidades. 
Determinantes sociais nas escolhas profissionais: uma análise sobre o curso normal.

Revista Ensaios, vol. 15, jul-dez de 2019.

\begin{abstract}
Não é por acaso que, em todas as encruzilhadas do cursus escolar (e em todas as reviravoltas da carreira intelectual) apresenta-se a "escolha" entre as estratégias daquele que "vive de rendimentos", empenhado na maximização da segurança que garante o que já adquiriu, e as estratégias do especulador que visa maximizar o lucro: os ramos de ensino e as carreiras de maior risco, portanto, normalmente, as de maior prestígio, têm sempre uma espécie de par menos glorioso, relegado àqueles que não possuem suficiente capital (econômico, cultural e social) para assumirem os riscos da perda total ao pretenderem ganhar tudo; tais riscos nunca são assumidos a não ser quando se tem a certeza de nunca perder tudo ao tentar ganhar tudo. (BOURDIEU, 1998, p.95).
\end{abstract}

A partir dessa discussão, pensar as escolhas profissionais já não nos parece tão natural. Pensando nisso, Paul e Silva (1998) já apontavam em seus estudos a presença do que chamam de uma "auto-seleção" feita pelos sujeitos no processo de "escolha" de suas carreiras. Agrupam então três conjuntos de variáveis que analisam nesse processo: variáveis pessoais, variáveis sociais e variáveis de êxito acadêmico. De acordo com Duru e Mingat (1979), "Os estudantes partem da hipótese de que os cursos que apresentam taxas de êxito mais fracas, ou seja, os mais exigentes, são justamente aqueles que conduzem a remunerações mais elevadas e ponderam entre o rendimento e a probabilidades de não completar os estudos" (apud PAUL; SILVA, 1998, p.116).

Paul e Silva (1998) ainda alertam para o entendimento de que essa escolha, para além de acadêmica, "também sugere uma auto-seleção apoiada nas características sócioeconômicas e de sexo dos candidatos" (p.121). Em diálogo com as ideias de Bourdieu discutidas acima, os autores adicionam a variável sexo, que vem influenciar e diferenciar em alguns aspectos a escolha na formação dos indivíduos, demonstrando que algumas carreiras tendencialmente são mais escolhidas por homens, enquanto outras, como a própria docência, são mais escolhidas por mulheres.

Tendo em vista o debate desenvolvido, entendemos então que essa predominância não se dá de maneira espontânea, e se existem mais mulheres no magistério, essa realidade reflete um desdobramento estrutural da própria sociedade. Se os estudantes tendem a selecionar cursos no ensino superior que primordialmente colocam como mais possíveis dentro de suas realidades, de acordo com tempo de estudos, deslocamento, necessidade de trabalhar, gênero e etc, estes direcionam, consequentemente, seus futuros, baseados nas possibilidades que lhes é cabível. A causalidade do provável, como indica Bourdieu, reflete-se ao longo da trajetória escolar e profissional desses indivíduos, desde 
Determinantes sociais nas escolhas profissionais: uma análise sobre o curso normal.

Revista Ensaios, vol. 15, jul-dez de 2019.

as possibilidades que lhes são postas, até as escolhas feitas dentro dessas possibilidades. Aqueles que, com efeito, podem fazer escolhas, dentro de uma gama de possibilidades ao longo da trajetória, diferenciam-se quase que em totalidade daqueles que são levados a "escolhas possíveis", dentro de um contexto de uma ou poucas possibilidades.

Segundo Nogueira (2005), os alunos que apresentam melhor situação socioeconômica e acadêmica, entre outras coisas, possuem uma tendência em escolher cursos de mais difícil acesso, considerados de maior prestígio e que, consequentemente, abrem maiores perspectivas de rendimento financeiro. Já os estudantes que possuem situação socioeconômica mais desfavorável, pelo contrário, tendem a buscar os cursos de mais fácil acesso, mais desprestigiados e que, consequentemente, formam esses estudantes para profissões que, dentro da estratificação das ocupações, terão menores retornos financeiros.

De um modo geral, os indivíduos oriundos das camadas superiores da sociedade ingressavam nos cursos mais prestigiados do sistema universitário francês. Os membros das camadas inferiores, ao contrário, quando chegavam ao ensino superior, eram relegados aos cursos e faculdades de menor prestígio. Em relação às mulheres, da mesma forma que foi observado no caso brasileiro, Bourdieu já destacava que, embora suas probabilidades de ingresso no ensino superior fossem próximas às dos homens, elas tendiam, na época, a se restringir às humanidades e às carreiras voltadas para o magistério. As pesquisas estrangeiras mais recentes - por exemplo, Duru e Mingat, 1979, 1988; DuruBellat, 1995; Ball et alii, 2001; Reay et alii, 2001; Broady et alii, 2002 continuam reiterando, cada vez com maior riqueza de detalhes, essas mesmas observações. Elas deixam claro que, de um modo geral, os indivíduos não escolhem seus cursos superiores de maneira aleatória, a partir de atributos de caráter idiossincrático, mas em função de suas características socioeconômicas e acadêmicas, do seu gênero, de sua idade e de seu pertencimento étnico. (NOGUEIRA, 2005, pp. 4-5).

A formação de professores ocupa um lugar de pouco prestígio no sistema de ensino superior brasileiro. Muito tem se escrito sobre a desvalorização da ocupação docente (Masson, 2017; Schwartzman, 2003) e seu reflexo no perfil socioeconômico dos professores. Neste artigo, busca-se avançar nessa discussão lançando luz sobre a estratificação dentro da ocupação. Isso porque a desvalorização da profissão atinge com mais força o grupo que está na base da estratificação docente, que são justamente os professores habilitados em nível médio para docência dos anos iniciais do ensino básico. 
Determinantes sociais nas escolhas profissionais: uma análise sobre o curso normal.

Revista Ensaios, vol. 15, jul-dez de 2019.

Se dentro da hierarquia das ocupações o professor já ocupa um dos lugares mais baixos da hierarquia ocupacional, os professores dos anos iniciais, muitos destes com formação no curso médio normal, ocupam um lugar ainda mais desprestigiado. O que se mostra mais comum é que os professores com formação em nível médio acabam por estarem mais na educação infantil e nas séries iniciais da educação básica do que em outras etapas. "Esses dados estão em conformidade com o que estabelece a LDB, ao admitir formação de nível médio para essas etapas.” (INEP, 2018 p.39).

Ou seja, dentro de um sistema de exclusão, que dita quais são as profissões mais prestigiadas, quais são as menos prestigiadas, quais são as mais importantes, quais são as menos importantes, o professor dos anos iniciais muitas vezes sofre com esse processo de exclusão de maneira ainda mais acentuada do que, por exemplo, os professores das séries finais do ensino fundamental e médio. Um estudo feito pelo Instituto Nacional de Estudos e Pesquisas Educacionais Anísio Teixeira (INEP, 2018), a partir da análise do perfil do professor da Educação Básica, reforça o papel desvalorizado desse docente da educação infantil e dos anos iniciais.

\begin{abstract}
Observa-se que professores com nível médio de escolaridade estão mais presentes nas regiões rurais do que nas urbanas; e professores com formação de nível superior estão mais presentes nas regiões urbanas. Isso pode refletir o desinteresse de professores com formação mais elevada em trabalhar nas regiões rurais, possivelmente por fatores como a distância em que se encontram as escolas e os baixos salários que são oferecidos nessas regiões. Provavelmente esses profissionais mais qualificados encontram melhores colocações em regiões urbanas, e pessoas que aceitam trabalhar nas regiões rurais são as que têm escolaridade menor (pois é onde encontram oportunidades). É uma situação que espelha a desigualdade regional do País. (INEP, 2018, p.41).
\end{abstract}

De modo que dentro da própria ocupação, os docentes de anos iniciais encontramse em condições de trabalhos piores que os demais docentes que geralmente ocupam outros segmentos de ensino. Muitas vezes por um desprestígio atribuído ao nível de formação, como também a própria desvalorização dentro de um sistema que prioriza as certificações. Muitas dimensões podem ser analisadas nesse contexto de estratificação que diferenciam esses profissionais, como sexo, cor/raça, idade, escolaridade do professor e afins. No caso do sexo, mais uma vez essa diferenciação se sai predominantemente forte na presença de mulheres quando se trata de séries iniciais em detrimento de um aumento da participação masculina quando se vai aumentando as séries de atuação. 
Determinantes sociais nas escolhas profissionais: uma análise sobre o curso normal.

Revista Ensaios, vol. 15, jul-dez de 2019.

O que se percebe então é que, contrariando a ideia de vocação que se discutiu inicialmente, o que se tem visto até aqui são trajetórias educacionais e ocupacionais determinadas por características socioeconômicas que se perpetuam ao longo das trajetórias. Logo, se as mulheres são maioria na base da ocupação docente, entende-se que as trajetórias pessoais dessas mulheres também são afetadas e condicionadas por suas trajetórias escolares e profissionais,

A questão da distribuição por gênero em torno da formação profissional tem sido debatida por diversos estudiosos que mostram uma tendência de concentração da mão de obra feminina em carreiras relacionadas à esfera do "cuidar" (magistério, por exemplo) enquanto os homens se concentram nas áreas tecnológicas e exatas. Apesar de ter sido, em suas origens, uma atividade preponderantemente masculina, o magistério infantil é hoje uma área dominada pelas mulheres. O predomínio delas nesse contexto veio acompanhado de uma maior desqualificação, declínio da remuneração e de prestígio da carreira. De acordo com Costa (1983) o magistério primário é uma espécie de "gueto de mão-de-obra feminina". (ZUCCARELLI, 2015, pp. 1112).

Importante considerar que o curso normal atrai hoje poucos alunos no contexto do ensino médio. Em 2011, apenas 1,5\% das matrículas foram feitas nesse segmento (ZUCCARELLI, 2015) e as diretrizes nacionais de formação de professores indicam que a formação de professores para a educação básica deve priorizar a certificação dos docentes em licenciaturas plenas. E ainda, de acordo com Assis (2015):

A premissa de que os alunos egressos dos Cursos de Formação de Docentes, modalidade Normal, em sua denominação atual, ainda encontram lugar apesar das recomendações legais, impõe a reflexão sobre outros aspectos intrinsecamente ligados, referentes à formação, ao trabalho e à carreira docente neste momento histórico, entre eles a baixa procura pelos cursos de licenciatura, o que reflete o desinteresse pela carreira docente, o desprestígio social, a baixa remuneração e as condições de trabalho adversas. Some-se a isto a discrepância entre a extensão da obrigatoriedade e consequente expansão da oferta da Educação Básica, e a capacidade de formação de professores para atender a esse crescimento para atender tal demanda. (ASSIS, 2015, p. 39982).

A partir desse debate, uma questão fundamental que se coloca é entender os motivos que levam os estudantes a buscarem a formação no Ensino Normal. É por isso que o próximo item apresenta, em um primeiro momento, a metodologia empregada na pesquisa, para, em seguida, apresentar a discussão dos resultados observados. 
Determinantes sociais nas escolhas profissionais: uma análise sobre o curso normal.

Revista Ensaios, vol. 15, jul-dez de 2019.

\title{
2) Formação docente e vocação profissional
}

Ainda que enfrentando historicamente um amplo processo de intermitência, o curso normal, em seu início frequentado majoritariamente por homens, sofreu diversas mudanças ao longo de sua trajetória e exerceu papel importante na oferta de educação básica. Segundo Saviani,

\begin{abstract}
A Província do Rio de Janeiro sai à frente, instituindo em Niterói, já em 1835, a primeira Escola Normal do país. Esse caminho foi seguido pela maioria das províncias ainda no século XIX, na seguinte ordem: Bahia, 1836; Mato Grosso, 1842; São Paulo, 1846; Piaú́, 1864; Rio Grande do Sul, 1869; Paraná e Sergipe, 1870; Espírito Santo e Rio Grande do Norte, 1873; Paraíba, 1879; Rio de Janeiro (DF) e Santa Catarina, 1880; Goiás, 1884; Ceará, 1885; Maranhão, 1890. Essas escolas, entretanto, tiveram existência intermitente, sendo fechadas e reabertas periodicamente. (SAVIANI, 2009, p. 144).
\end{abstract}

A pesquisa foi realizada no Instituto de Educação Professor Ismael Coutinho, (IEPIC), durante o estágio obrigatório feito na instituição no ano de 2019, como parte da exigência para obtenção do título de licenciada em Ciências Sociais. O IEPIC encontrase no bairro de São Domingos, em Niterói, no Estado do Rio de Janeiro. É a primeira instituição brasileira com foco para a formação de professores. Fundado em 1835, hoje é uma instituição de grande reconhecimento e importância para o município devido seu passado histórico e presente atuação na educação do município. Situa-se entre o centro da cidade e a Universidade Federal Fluminense (UFF), recebendo alunos de diferentes regiões e camadas sociais. Pela sua proximidade com a Universidade Federal Fluminense - UFF, recebe também uma grande quantidade de estagiários docentes nas mais diversas áreas.

A formação de professores no IEPIC dá-se em três anos. Compõe-se de disciplinas do curso básico para ensino médio e das disciplinas pedagógicas, específicas para a formação de professores. Em período integral, os alunos precisam também cumprir carga horária de estágio obrigatório, distribuída ao longo dos quatro bimestres em cada um dos três anos de formação e, concomitantemente, necessitam realizar atividades culturais complementares para a formação.

Pensar os alunos analisados nesse processo de pesquisa é fundamental para refletirmos sobre quem são esses estudantes. É por isso que aqui analisa-se as entrevistas 
Determinantes sociais nas escolhas profissionais: uma análise sobre o curso normal.

Revista Ensaios, vol. 15, jul-dez de 2019.

realizadas para a pesquisa, procurando traçar um perfil desses estudantes pesquisados. Foram estabelecidos três eixos de análise dentre as sete perguntas dos questionários: motivações para a escolha do curso normal; perfil socioeconômico e aspirações profissionais.

As entrevistas para a pesquisa foram realizadas com dez estudantes, seis mulheres e quatro homens, todos estudantes do curso normal, dos três anos do ensino médio. A quantidade de homens entrevistados é consideravelmente importante, visto que algumas turmas possuem apenas um ou dois alunos homens, em uma turma de trinta ou mais estudantes.

Do ponto de vista da motivação para a escolha do curso normal, dentre os estudantes entrevistados, apenas dois apontaram como primeira opção o interesse em permanecer em alguma área que leve à continuação na docência. Os outros oito estudantes vislumbram na conclusão do curso normal uma possibilidade aparentemente rápida em conseguir um emprego até que alcancem seus outros objetivos, em diversas áreas, desde medicina até engenharia naval, como foram citadas em algumas entrevistas.

Nenhum dos entrevistados mora perto da escola, sendo necessário o uso de algum tipo de transporte para chegarem a ela. O fato não deixa de ser curioso, visto que, na fala de alguns dos entrevistados, a escola era apontada como sendo uma das mais próximas de casa. Esse pode ser um indicativo de que a proximidade não é um fator primordial na escolha pela escola e, de que esses alunos podem fazer uso dessa fala para, de alguma maneira tentar justificar a escolha pelo normal ainda que não representando sua maior vontade. Em muitas falas, aparece o fator "o peso que o IEPIC tem", indicando a qualidade e a tradição do Instituto. Muitos desses estudantes reconhecem o colégio como um facilitador, como metaforicamente "um portão de entrada" para possibilidades futuras. Em uma das entrevistas, chega-se a dizer "Quando eu vim pra cá a minha ideia era ter um emprego assim que eu terminasse a escola. O IEPIC tem um nome tão grande nesse quesito, por ser a primeira escola de formação de professores da América Latina, que com o seu currículo, você saindo formada pelo IEPIC, você consegue entrar para qualquer escola.”. Nota-se então, que a busca por esse diploma, ainda que muitas das vezes não almejada como primeira opção, demonstra a busca pela praticidade e pelo 
Determinantes sociais nas escolhas profissionais: uma análise sobre o curso normal.

Revista Ensaios, vol. 15, jul-dez de 2019.

pragmatismo que esse diploma pode representar, relacionando-se inclusive com os grupos sociais aos quais esses estudantes pertencem.

Com isso, o que percebemos é que o ideário de uma possibilidade de prestígio na formação influencie muitos desses estudantes a permanecerem, ainda que não intencionando prosseguir na docência. No entanto, a noção de prestígio em sua formação se confunde com as possibilidades de oportunidades concretas no mercado de trabalho. Nota-se que os alunos no primeiro ano, em geral, sentem mais incerteza sobre a continuação no curso, processo que se modifica ao longo do ciclo de formação, quando os alunos passam a ter mais certeza sobre a conclusão. Os estudantes identificam esse prestígio nas falas de seus professores, nas falas dos colegas e muitas vezes dos familiares. Não à toa, essa possibilidade do prestígio na formação e consequentemente um imaginário de maior chance de emprego, pode ser um dos fatores que levam esses estudantes a continuarem no curso normal, ainda que inicialmente não o tenham escolhido como primeira opção. Em uma das entrevistas a estudante diz que, embora não fosse a profissão dos sonhos (ser professora), por desejar ter uma profissão mais garantida ao sair do ensino médio, escolheu o IEPIC, e conta admirar a profissão, já que a mãe foi normalista e hoje é pedagoga e a irmã é professora de Educação Física. Relata que no fim das contas “acabou pegando o gosto" e terminará o normal.

Do ponto de vista do perfil socioeconômico, três alunos declaram que a renda familiar está entre ou acima de 2 salários mínimos. Os demais se dividem entre não saber dizer um valor, outros vivem da aposentadoria de algum avô/avó, um estudante relata o recebimento do bolsa família, outro estudante diz não terem uma renda fixa familiar pois o pai é autônomo.

Ainda que com essa inconsistência na definição de uma renda mensal, nesse um ano de estágio acompanhando as turmas, é possível notar algumas coisas que me levam a algumas conclusões, talvez não tão assertivas, pois pautadas em minha observação participante ao longo do estágio. Dentre os alunos que não sabem dizer ao certo o valor da renda mensal da família, recordo-me de duas aulas de sociologia nas quais uma das estudantes se mostrava estafada e desatenta. Quando questionada por tal comportamento, rapidamente a resposta que procurava protegê-la de uma "possível bronca", foi de 
Determinantes sociais nas escolhas profissionais: uma análise sobre o curso normal.

Revista Ensaios, vol. 15, jul-dez de 2019.

encontro com a justificativa de precisar trabalhar informalmente alguns dias da semana, conciliando estágio obrigatório e as aulas da escola, ao passo que algumas estudantes se aproveitam da fala da colega para justificarem alguns comportamentos parecidos do mesmo ou de outros dias.

Ainda que a maioria dos entrevistados não trabalhe, a necessidade de trabalhar aparece na fala de alguns deles. Os que trabalham, fazem algo no setor informal, fazem "bicos" pois encontram nestes uma forma de conciliar trabalho, estudo e estágio obrigatório. Em quase todas as entrevistas reclamações sobre o horário integral e a carga horária de estágios obrigatório são recorrentes, justamente devido à dificuldade de trabalhar que esses estudantes encontram.

O próprio uso do uniforme no colégio, pode ser um ponto de reflexão. O IEPIC não possui mais obrigatoriedade no uso do uniforme escolar desde a ocupação dos estudantes em 2016. Pensando nisso, é no mínimo curioso o fato de alguns alunos usarem sempre o uniforme escolar e, vale pensar se isso não reflete por vezes a falta de opção por outras roupas para ir à escola.

Retomando a discussão acerca da não proximidade da escola com a casa dos estudantes entrevistados, vale a problematização que se deve fazer sobre os esforços desses estudantes que, mesmo afirmando muitas vezes que estudam no IEPIC "por ser mais próximo de casa", moram em bairros afastados, necessitando muitas vezes de algum meio de transporte para chegar a escola. Os estudantes entrevistados se dividem nas seguintes localidades: três moram em São Gonçalo, um no Barreto, um na Alameda, dois em Piratininga, dois no Largo da Batalha e um no Rio D’Ouro. Em todos esses lugares seria possível aos estudantes a opção por outra escola, de fato mais próxima de suas casas. Cabe então notar que, em suas falas, o fator "prestígio" em relação ao colégio pode ser fator determinante para que esses permaneçam nesse espaço, ainda que necessitando um esforço maior para chegar na escola todos os dias.

Nesse aspecto, cabe pontuar que, ao optarem por esse deslocamento diário, ainda que possuindo outras escolas em suas regiões, isso já demonstra, que esses estudantes, ainda que muitas vezes desprivilegiados socialmente, possuem condições diferentes de muitos estudantes da realidade do ensino médio brasileiro. Essa dedicação no 
Determinantes sociais nas escolhas profissionais: uma análise sobre o curso normal.

Revista Ensaios, vol. 15, jul-dez de 2019.

deslocamento exige, antes de mais nada, investimento financeiro que possibilite que isso aconteça.

Do ponto de vista das aspirações profissionais um aspecto importante que deve ser ressaltado foi a presença de apenas dois estudantes que se identificam efetivamente com a docência e que foram para o curso normal tendo uma perspectiva mais evidente sobre o mesmo e com intenções de prosseguirem no magistério.

Aqui, a perspectiva de Bourdieu (1998) notoriamente se mostra presente, trazendo a reflexão da causalidade do provável como atuante e definidor na vida de muitos desses jovens. Discursos como, “Acabei caindo aqui no colégio pela matrícula fácil”, “A escola é boa, aí acabei vindo pra cá mesmo", "Minha mãe quem me colocou aqui, ela acreditou que seria melhor pra mim"; são recorrentes e repetem-se nas entrevistas, com discursos diferentes, com histórias diferentes, que levam esses alunos muitas vezes a perfis bem parecidos.

Ou seja, dizer que os alunos do curso normal estão naquele ambiente por escolha e por querer lecionar, já não cabe discussão, visto que em um universo de dez, apenas dois estudantes apontaram essa predisposição e os demais, muitos aspiram para outras carreiras, que em geral, se distanciam da docência.

\section{3) Considerações finais:}

Buscando analisar em que medida a "escolha" pelo curso normal relacionava-se com as origens socioeconômicas dos indivíduos, a justificativa através da vocação para algumas "escolhas" profissionais mostrou-se insuficiente, uma vez que fica evidente uma relação entre a classe social a que os sujeitos pertencem e suas possibilidades de escolhas para determinadas profissões.

Respaldando-se em alguns conceitos importantes dentro do debate de desigualdades de oportunidades e estratificação ocupacional, Bourdieu colabora com o debate com seu conceito de causalidade do provável, que nos ajuda a identificar como 
Determinantes sociais nas escolhas profissionais: uma análise sobre o curso normal.

Revista Ensaios, vol. 15, jul-dez de 2019.

muitos indivíduos acionam estratégias e fazem escolhas dentro das oportunidades (algumas poucas) que lhes são possíveis.

Ao longo de um ano de observação e pesquisa, o que se mostra em muitos momentos é que, mesmo com muitos estudantes não pretendendo necessariamente prosseguir na docência ao decorrer de suas vidas, muitos destes veem no curso normal uma possibilidade "rápida" e aligeirada de emprego ao término do ensino médio. Dentro dessas perspectivas que talvez se possa acreditar que muitos desses estudantes estejam vislumbrando o curso normal como uma possibilidade de "mudança de vida", ou seja, vislumbrando uma possibilidade de ascensão social.

Se inicialmente a hipótese era de que os determinantes sociais e econômicos influenciavam na escolha desses alunos pelo curso normal, ao final desta pesquisa evidencia-se que a "não escolha" também se relaciona a esses determinantes. Por meio das entrevistas realizadas com alunos das três séries do curso normal, através da minha observação participante no ambiente de curso normal, o que se mostrou mais latente e comum, foi que muitos desses estudantes sequer escolheram estar ali. Muitos deles, através da matrícula fácil, por decisão familiar e outros, chegam ao curso normal sem ao menos saberem o que este significa necessariamente. $O$ que parece é que o perfil socioeconômico desses estudantes é por vezes regular e sistemático com os dados encontrados através do Inep, e que o discurso acionado para justificar a passagem pelo curso normal tem a ver com alguns fatores como o prestígio que vislumbram na instituição de ensino a que pertencem, para além da possibilidade mais imediata de inserção no mercado de trabalho. Enquanto que para alunos de origem socioeconômica mais prestigiada, a possibilidade mais imediata é o acesso ao ensino superior, e isso já acaba por ser um indicativo forte das condições socioeconômicas desses estudantes.

Assim, ressalta-se que, em realidade, o processo de escolha continua sendo privilégio não acessado por todos. Os estudantes que escolhem pelo curso normal com consciência ao fazê-lo, com noção prévia deste, com real intenção e com objetivo de prosseguir na docência, são minoria.

Entretanto, convém aqui pontuar que, mesmo sendo minoria, muitos desses alunos ao ingressarem no curso normal, vislumbram na docência uma possibilidade de mudança, 
Determinantes sociais nas escolhas profissionais: uma análise sobre o curso normal.

Revista Ensaios, vol. 15, jul-dez de 2019.

ou de, no mínimo, um respaldo financeiro ao terminar o ensino médio e até alcançarem outros objetivos pessoais. Seguindo a lógica de Bourdieu, podemos entender que muitos desses estudantes se apropriam de manobras dentro desse campo, para conseguirem fazer parte do "jogo". Se isso é bom ou ruim, vale também uma reflexão, principalmente por pensarmos os profissionais da educação que estão sendo formados para atuarem sem necessariamente estarem compromissados com aquela função.

Porém, o que se nota é que o curso normal tem sido um grande impulsionador de estudantes que ingressam nas licenciaturas, em geral, e principalmente, para a pedagogia. No entanto, esse acesso ao curso superior nem sempre está relacionado à procura por maiores aprendizados e especialização. O que se tem notado nos últimos tempos, como se percebe em muitas pesquisas, é uma busca de acesso ao ensino superior, por conta da necessidade de maior certificação para a competição no mercado de trabalho. O que se percebe prejudicial, já que ao voltar os olhos para a valorização da certificação, muita das vezes se escapa aos olhos a qualidade dessa formação.

Ainda assim, é necessário pontuar que mesmo com uma aparente melhoria e ampliação, ainda é privilégio de uma parcela da sociedade o acesso ao ensino superior. Logo, não é uma realidade, tampouco uma verdade, que todos esses alunos acessarão o ensino superior ao finalizarem o curso normal. Muitos desses alunos contam justamente com a formação profissionalizante já no ensino médio, como garantia para uma profissão, muitas vezes sem esperançar o curso superior para tal. Assim, a busca pelo ensino superior torna-se muitas vezes a busca por credenciais que posicionam socialmente melhor o professor no mercado de trabalho, não significando necessariamente maior especialização destes, já que nem sempre mais credenciais significarão mais conhecimento.

Nesse sistema que visa o credenciamento, os professores da base, geralmente os que estão alocados nas séries iniciais, são aqueles com as piores remunerações e condições de trabalho. Nesse ponto, é fundamental atentar para o fato de que, como visto, a maior parcela desses profissionais são mulheres, o que reforça o intenso debate que vem se fazendo acerca da "feminização da docência". Esse é um processo que contribui e reforça as desigualdades de gênero. 
Determinantes sociais nas escolhas profissionais: uma análise sobre o curso normal.

Revista Ensaios, vol. 15, jul-dez de 2019.

Se então, estamos pensando as discrepâncias desse processo, não nos cabe deixar de lado o papel que as mulheres ocupam nesses espaços que reforçam essas desigualdades e perpetuam a ideia geral desses papéis de gênero. Se para os professores da base as condições financeiras e de trabalho são difíceis, as mulheres que, em maioria, ocupam esses espaços são ainda as vítimas mais afetadas por esse sistema excludente e reforçador de estereótipos negativos.

Recentemente, um projeto de lei, vindo pelas deputadas estaduais do PSL de São Paulo, Janaina Paschoal, Leticia Aguiar e Valéria Bolsonaro, visa restringir às mulheres a exclusividade em atividades educativas do cuidado na Educação Infantil. Atividades essas como, dar banho, trocar fralda e ajudar a ir ao banheiro. A discussão já toma dimensões acaloradas, inclusive entre a comunidade pedagoga, visto que parte concorda com a decisão, indo na contramão do amplo debate que se tem buscado fazer acerca da ética do cuidado.

Um projeto de lei a esse nível, supõe que os homens que se destinam a exercer essa função são potenciais abusadores e, novamente, na divisão sexual do trabalho, destina às mulheres as tarefas do cuidado, reforçando mais uma vez todos os estereótipos de gênero que se luta por desconstruir. Colocar somente mulheres para as tarefas do cuidado, não inibe em nada práticas de abuso. Essas práticas não são cometidas pelo sexo de quem as comete, até porque, dados oficiais apontam que muitos desses abusos são acometidos dentro do próprio ambiente familiar. O que se precisa é educação sexual e orientação massiva aos profissionais, familiares e para os estudantes ao longo de sua formação escolar.

Perante essa discussão, conclui-se que segue sendo fundamental estudos como esse, assim como os mais diversos estudos acerca das desigualdades ocupacionais e de gênero. Visando o enfrentamento e a superação de muitos desses pensamentos e estereótipos, estruturalmente disseminado na sociedade, pesquisas como essas possuem importante papel de atuação frente a isso. A Educação possui papel indispensável nesse cenário e, mais ainda, perante os resultados desse trabalho, a formação docente em nível médio pode ser um desses lugares explorados e utilizados para a própria discussão de assuntos como o abordado na proposta de lei citada e, diversos outros assuntos, que 
Determinantes sociais nas escolhas profissionais: uma análise sobre o curso normal.

Revista Ensaios, vol. 15, jul-dez de 2019.

refletem diretamente no grupo que compõe o curso normal e que está saindo com a formação voltada para a atuação nesses anos iniciais da educação básica. Assim, que seja o curso normal em nível médio um campo exploratório e formativo que busque fazer a diferença na formação profissional e pessoal de seus estudantes. Através da Educação, através da formação contínua, através da valorização docente, do incentivo à pesquisa e ao aprimoramento profissional, que possamos vislumbrar nela e por meio dela, as potencialidades de mudanças sociais.

Recebido 28/11/2019. Aprovado 05/05/2020 
Determinantes sociais nas escolhas profissionais: uma análise sobre o curso normal.

Revista Ensaios, vol. 15, jul-dez de 2019.

\section{Referências Bibliográficas:}

ASSIS, L. L. O curso de formação de docentes, modalidade normal, em nível médio - questões atuais em perspectiva histórica. Educere - XII Congresso Nacional de Educação. Paraná, 2015

BARBOSA, Maria Ligia de Oliveira. Origem social e vocação profissional. In: HONORATO, G; HERINGER, R. (Orgs.). Acesso e sucesso no ensino superior: uma sociologia dos estudantes. Rio de Janeiro: Faperj/7Letras, 2015.

BISSERET, Noëlle. A ideologia das aptidões naturais. In: DURAND, José C. (org.). Educação e hegemonia de classes. Rio de Janeiro: Zahar, 1979.

BOURDIEU, P. Futuro de classe e causalidade do provável. In: NOGUEIRA, M. A. e CATANI, A. (Org.). Escritos de educação. p. 83-126. Petrópolis: Vozes, 1998.

BRASIL. Constituição da República Federativa do Brasil de 1988. Brasília, 1988. Disponível em: <http://www.planalto.gov.br/ccivil_03/constituicao/ConstituicaoCompilado.htm.>. Acesso em: 01 out. 2019.

BRASIL. Lei de Diretrizes e Bases da Educação Nacional. Lei número 9394, 20 de dezembro de 1996.

GALIZZI VIEIRA GOMIDE, Angela; BLANCK MIGUEL B, Maria Elisabeth. CURSO NORMAL: A FORMAÇÃ̃O DE PROFESSORES EM NÍVEL MÉDIO, NO PARANÁ (1996-2006). Revista Diálogo Educacional, [S.1.], v. 9, n. 27, p. 297-314, jul. 2009. ISSN 1981-416X. Disponível em: <https://periodicos.pucpr.br/index.php/dialogoeducacional/article/view/3583>. Acesso em: 05 out. 2019. doi:http://dx.doi.org/10.7213/rde.v9i27.3583.

MEC/INEP. Perfil do Professor da Educação Básica: Com base nos resultados do Censo Escolar da Educação Básica dos anos de 2009, 2013 e 2017. Brasília, 2018. Disponível em: <http://portal.inep.gov.br/informacao-da-publicacao//asset_publisher/6JYIsGMAMkW1/document/id/1473981>. Acesso em: 25/09/2019.

NOGUEIRA, Claudio M. M. Limites da explicação em sociologia da educação: considerações a partir de pesquisas sobre o processo de escolha do curso superior. In: XII Congresso Brasileiro de Sociologia, 2005, Belo Horizonte. XII Congresso Brasileiro de Sociologia, 2005.

PAUL, J., SILVA, N. do V. Conhecendo o seu lugar: A Auto - Seleção na Escolha da Carreira. Revista Brasileira de Política e Administração da Educação, Brasília, v.14, n.14, p. 115-130, jan./jun. 1998.

RIO DE JANEIRO. Secretaria de Estado de Educação. Portaria SEEDUC n. 91, de 29 de agosto de 2010.

RIO DE JANEIRO. Secretaria de Estado de Educação. Resolução SEEDUC n. 4.376, de 18 de dezembro de 2009. Estabelece a matriz curricular para curso de formação de 
Determinantes sociais nas escolhas profissionais: uma análise sobre o curso normal.

Revista Ensaios, vol. 15, jul-dez de 2019.

professores, em nível médio, na modalidade normal, da rede pública de ensino do Estado do Rio de Janeiro. Diário Oficial, Rio de Janeiro, 22 dez 2009.

SAVIANI, Dermeval. Formação de professores: aspectos históricos e teóricos do problema no contexto brasileiro. Rev. Bras. Educ. [online]. 2009, vol.14, n.40, pp.143155. ISSN 1413-2478. http://dx.doi.org/10.1590/S1413-24782009000100012.

WEBER, M. A ética protestante e o espírito do capitalismo. São Paulo: Editora Martin Claret, 2004.

ZUCCARELLI, C. Análise dos ingressantes no curso de pedagogia da UFRJ a partir de suas trajetórias no ensino médio. In: HONORATO, G.; HERINGER, R. (orgs.). Acesso e sucesso no ensino superior: uma sociologia dos estudantes. Rio de Janeiro: 7 Letras: FAPERJ, 2015. 